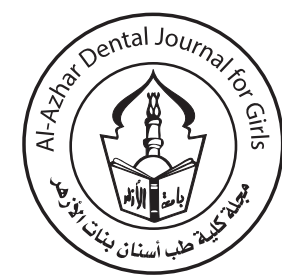

\title{
Effect of Etching Time and Bioglass Nanoparticle Incorporation in adhesive resin on Microtensile Bond Strength to Enamel
}

\section{Doaa A. Elsharkawy ${ }^{(1)}$}

Codex : 05/1901

azhardentj@azhar.edu.eg

http://adjg.journals.ekb.eg

DOI: $10.21608 /$ adjg.2018.6294.1059

\section{KEYWORDS}

enamel bonding,

etching time,

bioglass

\begin{abstract}
Purpose: The aim of the study was to evaluate the effect of addition of $20 \%$ bioactive glass nanoparticles (bioglass) to a universal adhesive on its microtensile bond strength to enamel etched for different times. Methods: Twenty eight enamel central incisor specimens were used in this study and divided into four groups; E1, E2, E3 and E4. E1 and E3 were bonded using unmodified universal adhesive while E2 and E4 were bonded using $20 \%$ bioglass modified adhesive. Groups E1 and E2 were etched with 37\% phosphoric acid for 30 seconds while E3 and E4 were etched for 6o seconds. Adhesive was applied to the enamel surface using a microbrush. Adhesive was left undisturbed on the enamel surface for 20 seconds for group 1and 2 or 30 seconds for gp 3 and 4 before curing. Composite resin was built up and the specimens were subjected to microtensile bond strength testing. Results: Data was analyzed using T-test and one-way ANOVA. Results showed that bond strength values were statistically similar for both modified and unmodified adhesives. Thirty seconds etching time produced significantly higher bond strengths than sixty seconds etching for either adhesive. Conclusions: Within limitations of this study, it can be concluded that bioglass incorporation into the universal adhesive has no deleterious effect on bonding to enamel. Increasing the etching time is not recommended as it causes a loss of bond strength.
\end{abstract}

\section{INTRODUCTION}

The concept of bonding composite resin to tooth structure has historically started with enamel bonding. Enamel bonding based on acid etching with phosphoric acid has produced reliable and consistent results over the years. An intact enamel resin interface is the first line of defense against leakage and recurrent caries. Enamel bonding has also opened the gate to conservative esthetic treatments as in laminate veneers and ceramic orthodontic brackets. Modifications have been introduced to the bonding systems, especially the addition of nanofillers ${ }^{(1,2)}$. Some of these fillers have aimed to improve the bond strength or bond

1. Lecturer of Operative Dentistry, Faculty of Dental Medicine for Girls, Alazhar University, Egypt 
durability while others encourage remineralization of tooth structure ${ }^{(3)}$. The addition of nanofillers to the adhesive resin however may have an effect on its composition and properties especially viscosity. Additional fillers should not hinder resin infiltration or affect the bond strength. How the addition of these nanoparticles to the adhesive affects the bond to the tooth must be evaluated. A balance between achieving a proper bond and the desire to prevent demineralization has to be reached for a successful outcome.

Among these fillers is bioactive glass (bioglass) which has been added to adhesives to enhance the remineralization of tooth structure adjacent to $\mathrm{it}^{(4,5)}$. Bioglass has been used in deep caries management, added to tooth pastes for enamel repair, and used in gels for reversing effects of bleaching ${ }^{(6,7)}$. The bioglass addition to the adhesive system can influence demineralization and remineralization cycles and may help in management of white spot lesions around orthodontic brackets that are bonded using adhesive systems. However, prior research investigating the effect of addition of bioglass nanoparticles to a universal adhesive has shown a significant reduction in bond strength of a universal adhesive to dentin ${ }^{(8)}$. This was more pronounced with addition of $20 \%$ by wt. bioglass. Self etch bonding with bioglass filled adhesives to dentin has also shown to be adversely affected. On the other hand, bonding to enamel has a different pattern all together than dentin due to the difference in microstructure and the bioglass filled adhesive might behave differently in enamel.

Acid etching with phosphoric acid has been the hallmark of enamel etching since being introduced by Bunocore in the fifties ${ }^{(9)}$. The variations of concentration and time for application have also varied over time ${ }^{(10)}$. It had been a fairly common practice to use $37 \%$ phosphoric acid for 60 seconds $^{(11,12)}$. With the introduction of dentin etching, the times have been reduced to 30 seconds and 15 seconds without apparent loss of bond strength ${ }^{(13)}$. The adhesive is then recommended to be given a space of $15-20$ seconds for penetration/infiltration into the micropores before polymerization. However, bioglass nanoparticle incorporation may cause changes in the adhesive. Adhesive regimen may be modified to accommodate for the expected increase in viscosity. Infiltration of the adhesive into tubules depends on several factors including viscosity, surface tension, contact angle, pore radius and penetration time ${ }^{(14,15)}$. Infiltration has been shown to increase with increasing the time allowed and decreases with increased viscosity ${ }^{(16)}$. Sixty seconds of etching has been shown to produce a rougher enamel surface than 30 seconds etching, which might aid in increasing micro-retention and bonding ${ }^{(5)}$. Extra infiltration time could allow for better penetration with a rougher enamel surface and thus a better bond. This study focuses on investigating the effect of a modified adhesive by bioglass nanofillers incorporation and a modified adhesive technique ( $60 \mathrm{sec}$ etch time $+30 \mathrm{sec}$ infiltration time) on the microtensile bond strength to enamel. The null hypothesis tested is that the incorporation of $20 \%$ bioglass nano particles to a universal adhesive and increasing the etching time has no effect on its microtensile bond strength to enamel.

\section{MATERIALS AND METHODS}

\section{Adhesive Modification:}

Bioglass nanoparticles were synthesized using the alkoxide sol-gel technique (Nanostream, Egypt). Silicon and phosphorus alkoxides were used with calcium hydroxide and sodium hydroxide. Deionized water and ethanol were used as solvents and the resultant gel was aged for one week at $70^{\circ} \mathrm{C}$ and at $\mathrm{pH}$ of 2 . It was heat treated at a temperature of up to $800^{\circ} \mathrm{C}$. Characterization of the particles was done using transition electron microscope to identify particle shape and size. Nano particles were spherical and of average size of $10 \mathrm{~nm}$. Nano particles were then weighed in order to be added to the adhesive in a concentration of $20 \%$ wt./vol., where $0.2 \mathrm{gm}$ was added to each $1 \mathrm{ml}$ of adhesive. The adhesive (Single Bond Universal, 3M) was 
drawn from its bottle using a wrapped plastic needle. The adhesive was then dispensed into an empty clean amalgam capsule together with the nano particles. The capsule was then placed in an amalgamator for mixing of the nano particles and adhesive for thirty seconds at $4400 \mathrm{rpm}$. The capsule was then opened and the adhesive was withdrawn into a clean wrapped syringe till specimen bonding.

\section{Bonding procedures:}

A total of 28 enamel specimens were used in this study providing 7 specimens per group. The labial surface of upper central incisors were used. They were divided into four groups according to the adhesive regimen used (table 1). Groups E1 and E2 were assigned 30 seconds etching time and 20 seconds adhesive infiltration time while E3 and E4 were assigned to etching for sixty seconds and thirty seconds of adhesive infiltration time. Group E1 and E3 received unmodified adhesive (control) while E2 and $\mathrm{E} 4$ received nanoparticle modified adhesive.

Table 1. Adhesive regimen for each group:

\begin{tabular}{|c|c|c|c|}
\hline Group & Etching time & Adhesive used & $\begin{array}{c}\text { Adhesive infil- } \\
\text { tration time }\end{array}$ \\
\hline E1 & 30 seconds & $\begin{array}{c}\text { Unmodified } \\
\text { adhesive }\end{array}$ & 20 seconds \\
\hline E2 & 30 seconds & $\begin{array}{c}\text { Bioglass } \\
\text { modified }\end{array}$ & 20 seconds \\
\hline E3 & 60 seconds & $\begin{array}{c}\text { Unmodified } \\
\text { adhesive }\end{array}$ & 30 seconds \\
\hline 60 seconds & $\begin{array}{c}\text { Bioglass } \\
\text { modified }\end{array}$ & 30 seconds \\
\hline
\end{tabular}

All labial enamel surfaces were ground to a flat surface for bonding using a grinding wheel under water coolant followed by abrasive polishing paper to achieve a 4000 grit surface. $37 \%$ Phosphoric acid (Ultra-etch, Ultradent, USA) was applied to the surface for each group according to the adhesive regimen, either 30 seconds or 60 seconds. The etchant gel was then rinsed for 15 seconds and gently air dried. The adhesive resin was applied to the etched enamel surface using a microbrush. Adhesive was left for 20 seconds before curing in groups E1 and $\mathrm{E} 2$, while it was left for 30 seconds in the E3 and E4 groups. The adhesive was then gently air thinned. The adhesive was then light cured with a LED unit for 20 seconds. Composite resin (Z250, 3M) was used for buildup in two increments of $2 \mathrm{~mm}$ each. Composite was applied to the bonded surface using a plastic instrument. Each increment was light cured for 40 seconds. All specimens were stored in tap water for $24 \mathrm{hrs}$ till testing. For beam preparation, the roots were cut off using a diamond disk and the crowns were fixed to acrylic resin blocks using composite resin with the labial surface facing upwards. The teeth were then mounted into a diamond saw machine (Isomet 4000, Bueheler Ltd., USA). The specimens were sectioned into $1 \mathrm{~mm}$ thickness slabs with a $0.3 \mathrm{~mm}$ thick diamond disc at $2050 \mathrm{rpm}$ under water coolant. They were then sectioned longitudinally into beams of approximate cross section diameter of $1 \mathrm{~mm}$. They were then cut horizontally to separate the individual beams. Two central beams were taken from each tooth and used for measurement. The readings for the beams of each group were pooled together to give an average.

\section{Microtensile bond strength testing}

For microtensile bond strength testing, each beam was attached to a special jig in a universal testing machine (Instron testing machine). The microtensile bond strength ( $\mu$ TBS) was determined as the samples were submitted to a tensile force at a crosshead speed of $1 \mathrm{~mm} / \mathrm{min}$ and $500 \mathrm{~N}$ until failure. Load required to debond each specimen was recorder using computer software. After testing, samples were removed from the fixtures with a scalpel. Data was collected for statistical analysis.

\section{Statistical analysis}

Statistical analysis was performed using a commercially available software program (SPSS 19; SPSS, Chicago, IL, USA). T test was used for comparison between groups. One way ANOVA test was used for comparison of all groups and two way ANOVA was used for analysis of effect of variable interaction. The level of significance was set at $\mathrm{P}<0.05$. 


\section{RESULTS}

Results of comparison of microtensile bond strengths in MPa and are shown in table 2 and 3. When comparing the effect of adhesive modification by addition of $20 \%$ bioglass, it was apparent that the bioglass modification did not change the bonding strength to enamel with either etching time. A non- statistically significant difference between unmodified (control) and 20\% modified was noted using 30 seconds etching $(\mathrm{p}=0.62)$ and 60 seconds etching $(\mathrm{p}=0.92)$.

Table (2) Comparison of microtensile bond strength between unmodified (control) and modified (20\%) adhesive ( $t$ test)

\begin{tabular}{|c|c|c|c|c|}
\hline & $\begin{array}{c}\text { Control } \\
\mathbf{3 0} \mathbf{~ s e c}\end{array}$ & $\begin{array}{c}\text { Modified } \\
\mathbf{2 0 \%} \mathbf{3 0} \mathbf{~ s e c}\end{array}$ & $\begin{array}{c}\text { Control } \\
\mathbf{6 0} \mathbf{~ s e c}\end{array}$ & $\begin{array}{c}\text { Modified } \\
\mathbf{2 0 \%} \mathbf{6 0} \mathbf{~ s e c}\end{array}$ \\
\hline Mean & 25.56 & 27.56 & 15.67 & 15.22 \\
\hline SD & 8.46 & 6.06 & 7.72 & 6.53 \\
\hline $\mathbf{t}$ & \multicolumn{2}{|c|}{0.51} & \multicolumn{2}{|c|}{0.1} \\
\hline $\mathbf{P}$ & \multicolumn{2}{|c|}{$0.62 \mathrm{~ns}$} & \multicolumn{2}{|c|}{$0.92 \mathrm{~ns}$} \\
\hline
\end{tabular}

Significance level $p<0.05, n s=$ non-significant

Regarding the effect of etching time, a statistically significant difference between the 30 and 60 seconds etching was noted in unmodified group (control) $(\mathrm{p}=0.04)$ and the modified $20 \%$ group as well $(\mathrm{p}=0.003)$. (Table 3$)$

Table (3) Comparison of max. load between 30 sec.etch time and $60 \mathrm{sec}$. (t test)

\begin{tabular}{|c|c|c|c|c|}
\hline & $\begin{array}{c}\text { Control } \\
\text { 30 sec }\end{array}$ & $\begin{array}{c}\text { Control } \\
\text { 60 sec }\end{array}$ & $\begin{array}{c}\text { Modified } \\
\text { 20\% 30 } \mathbf{~ s e c}\end{array}$ & $\begin{array}{c}\text { Modified } \\
\text { 20\% 60 sec }\end{array}$ \\
\hline Mean & 25.56 & 15.67 & 27.56 & 15.24 \\
\hline SD & 8.46 & 7.72 & 6.06 & 6.53 \\
\hline $\mathbf{t}$ & \multicolumn{2}{|c|}{2.28} & \multicolumn{2}{|c|}{3.66} \\
\hline P & \multicolumn{2}{|c|}{$0.04^{*}$} & \multicolumn{2}{|c|}{$0.003^{*}$} \\
\hline
\end{tabular}

Significance level $p<0.05$, *significant
Comparison between all subgroups (one way ANOVA) showed a statistically significant difference between all subgroups $(\mathrm{p}=0.036)$, where 30 seconds etching (control and 20\%) showed greater mean values than 60 seconds etching (control and $20 \%$ ), (Table 3)

Table (4) Comparison between all subgroups (one way ANOVA test)

\begin{tabular}{|c|c|c|c|c|}
\hline & $\begin{array}{c}\text { Control } \\
30 \mathrm{sec}\end{array}$ & $\begin{array}{l}20 \% \\
30 \mathrm{sec}\end{array}$ & $\begin{array}{c}\text { Control } \\
60 \mathrm{sec}\end{array}$ & $\begin{array}{c}20 \% \\
60 \mathrm{sec}\end{array}$ \\
\hline Mean & $25.56^{\mathrm{a}}$ & $27.56^{\mathrm{a}}$ & $15.67^{\mathrm{b}}$ & $15.24^{\mathrm{b}}$ \\
\hline SD & 8.46 & 6.06 & 7.72 & 6.53 \\
\hline $\mathbf{F}$ & \multicolumn{4}{|c|}{3.7} \\
\hline $\mathbf{P}$ & \multicolumn{4}{|c|}{$0.036^{*}$} \\
\hline \multicolumn{2}{|c|}{ Significance } & vel & 0.05 & significant \\
\hline
\end{tabular}

\section{Interaction of variables (two ways ANOVA)}

Two ways ANOVA revealed that adhesive modification had a non-statistically significant effect $(p=0.84)$, while the effect of etching time was statistically significant $(\mathrm{p}=0.049)$. The interaction of both variables had a non-significant effect $(\mathrm{p}=0.83)$, (Table 4)

Table (5) Two ways ANOVA Summary

\begin{tabular}{|c|c|c|c|c|c|}
\hline Source & SS & df & MS & $\mathbf{F}$ & $\mathbf{P}$ \\
\hline Adhesive modification & 4.54 & 1 & 4.54 & 0.04 & $0.8436 \mathrm{~ns}$ \\
\hline Etching time & 514.47 & 1 & 514.47 & 4.13 & $0.0493 *$ \\
\hline $\begin{array}{l}\text { Etching time } x \\
\text { adhesive } \%\end{array}$ & 5.82 & 1 & 5.82 & 0.05 & $0.8255 \mathrm{~ns}$ \\
\hline $\begin{array}{l}\text { Significance leve } \\
\text { significant }\end{array}$ & el $p<0$. & 05 & *sign & can & $n s=n o n$ \\
\hline
\end{tabular}




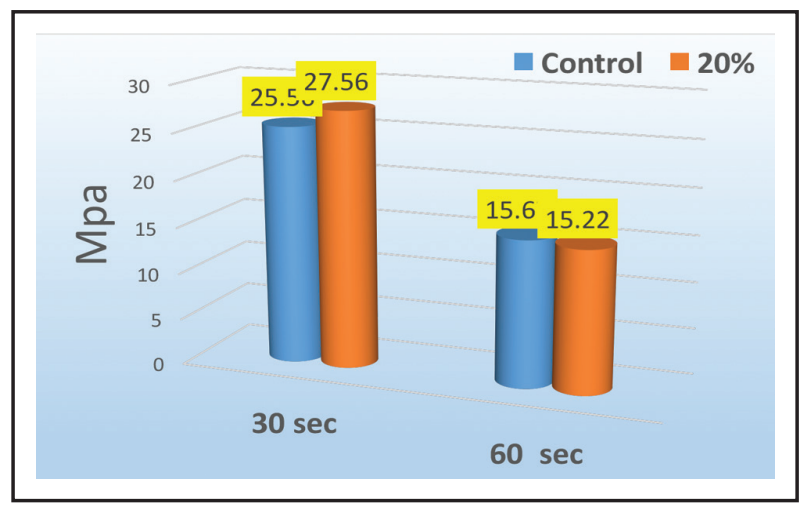

Fig. (1) Comparisom between unmodified (control) and modified adhesive with both etching times

\section{DISCUSSION}

Since the beginning of the age of dental bonding in the fifties, there have been numerous modifications to the materials and techniques. These modifications have predominantly aimed to improve the bond between the restoration and tooth structure and ensure its durability. Most of these modifications have been focused on the bond to dentin, as wall as aiming at prevent or arrest caries ${ }^{(17,18,19)}$. Modifications to improve enamel bonding have been less abundant in comparison, but the etching of enamel has been one of the most researched variables in enamel bonding ${ }^{(20)}$. The etching material, the time of application, the technique of application and the concentration of the acid have all been shown to affect the etching pattern and the bond strength of enamel ${ }^{(21)}$.

The modification of the adhesive by adding the bio active glass nanoparticles has been shown to enhance dentin remineralization but has been shown to have a deleterious effect on dentin bonding in both self etch and etch and rinse modes ${ }^{(6)}$. Their effect on enamel bonding however in this study have been shown to not adversely affect the bond. Bond strength for unmodified adhesive and nanobioglass incorporated adhesive have been shown to be similar. This difference might be due to the difference in histological structure and micromorphology between enamel and dentin bonds. While both bond- ing mechanisms depend on resin infiltration into micro pores created by etching, the enamel etching pattern with phosphoric acid especially type I and II removing the end of the enamel prisms and exposing the cores, is possibly easier for resin infiltration than the more delicate path of resin between the collagen fibrils of dentin to form the hybrid layer ${ }^{(22)}$. Bond viscosity, which has probably been altered by the addition of $20 \%$ bioglass fillers could be more of a factor in the dentin than the enamel. Our results suggest that enamel bonding can tolerate up to 25$30 \%$ filler loading as is the approximate filler loading in this study.

As for the etching time, the etching time had a significant effect on the bonding to enamel. Thirty seconds etching provided a significantly higher bond strength than that of 60 seconds. The sixty seconds provided for etching was chosen to evaluate its improvement of the bond as it creates a rougher surface that could aid in bonding ${ }^{(5)}$. The prolonged application time on the surface was also to allow for the more viscous adhesive to achieve optimum penetration ${ }^{(11)}$. However, this did not happen in this study. The bond decreased suggesting less resin infiltration into the micro pores, not more.

This is in disagreement with several studies that have shown 60 seconds to achieve better or same results as 30 seconds etching ${ }^{(23,8)}$. However, it is noted that most of these studies have used adhesives that are formulated with etch and rinse adhesives only. The adhesive used in this study is a self-etch adhesive as well and has a low $\mathrm{pH}$ of 2 . The addition of the adhesive to the surface and leaving it for 30 seconds on the surface before curing, on top of the 60 seconds of acid etching, could have simulated a situation of over-etching of enamel. Over etching of enamel has been shown to produce lower bond strengths ${ }^{(24)}$. The over etching produces over dissolving the outer prism area and can cause its breakdown into precipitates that indeed can block these micropores or obliterate them. This is in agreement with other studies that have shown the pore volume and size to decrease when etching enamel for 
60 seconds $^{(25)}$. Calcium precipitates in the micropores can cause incomplete infiltration into the enamel structure creating a compromised bond when compared to 30 seconds etching. The null hypothesis that etching time does not affect microtensile bond strength to enamel has been rejected.

\section{CONCLUSION}

The addition of bioglass nanofillers to an adhesive resin can be used without compromising the bond strength. This can be a valuable tool for prevention of white spot lesions. Etching time however is best used as the recommended 30 seconds.

\section{REFERENCES}

1. Keyf F, Ozlu S, Vural T, Denkbas EB. The effect of the nanofilled adhesive systems on shear bond strength of allceramics to dentin. SRM J Res Dent Sci 2015;6:75-81

2. Kasraei SH, Atai M, Khamverdi Z, Nejad SK. Effect of nanofiller addition to an experimental dentin adhesive on microtensile bond strength to human dentin. J Dent Tehran Univer Med Sci 2009;6:91-6.

3. Melo M, Cheng L, Zhang K, Weir M, Rodregues L, Xu H. Novel dental adhesives containing nanoparticles of silver and amorphous calcium phosphate. Dent. Mat. 2013; 29: 199-210

4. Suaro S, Osorio R, Watson TF, Toledano M. therapeutic effects of novel resin bonding systems containing bioactive glasses on mineral-depleted areas within the bondeddentine interface J Mater Sci. 2012; 23: 1521-32

5. Barkmeier WW, Erickson RL, Kimmes NS, Latta MA, Wilwerding TM. Effect of Enamel Etching Time on Roughness and Bond Strength. Oper Dent. 2009; 34: 217-22

6. Samuel S \&Marguerita F. Evaluation of NovaMin as an adjunct to fluoride for caries lesion remineralization. NovaMin Res Rep 2014; 32: 19-25

7. Gjorgievska E \& Nicholson J. Prevention of enamel demineralization after tooth bleaching by bioactive glass incorporated into toothpaste. Aust Dent J. 2011; 56:193-200

8. Elsharkawy DA. Effect of incorporation of bioactive glass nano particles in adhesive resin on microtensile bond strength to dentin in self etch and etch and rinse mode. ADJ-for Girls; 2018;5:399-404
9. Bunocore MIG. A simple method of increasing the adhesion of acrylic filling materials to enamel surfaces. J Dent Res. 1955; 34: 849-53

10. Pashley DHI, Tay FR, Breschi L Tjaderhane L, Carvalho RM, Carrilho M, Tezvergil-Mutluay. A state of the art etchand-rinse adhesives. Dent Mater; 2011; 27:1-16

11. Jia Jun Zhu, Alexander T.H. Tang, Jukka P. Matinlinna, Urban Hägg, Acid etching of human enamel in clinical applications: A systematic review. J Prosthet. Dent 2014; 112:122-35

12. Johanna C. Britton, Pamela Mcinnes, Roger Weinberg, William Ross Ledoux, Daniel Hugo Retief Shear bond strength of ceramic orthodontic brackets to enamel. Am. J. Orthod. Dentofac. Orthop. 1990; 98:348-353

13. Zhu JJ, Tang AT, Matinlinna JP, Hagg U. Acid etching of human enamel in clinical applications: a systemic review. J Prosthet Dent. 2014; 112:122-35

14. Fan PL, Seluk LW, O'Brien WJ. Penetrativity of sealants. J Dent Res 1975; 54: 262-4.

15. O'Brien WJ, Fan PL, Apostolides A. Penetrativity of sealants and glazes. The effectiveness of a sealant depends on its ability to penetrate into fissures. Oper Dent 1978; 3:51-6.

16. Paris S, Meyer-Lueckel H, C LFEN H and ielbessa A Resin Infiltration of Artificial Enamel Caries Lesions with Experimental Light Curing Resins Dent. Mat., 2007; 26: $582-8$

17. Tawfic HM, Niazy MA, Elsharkawy DA The Effect of Zn-doped Adhesive alone or Combined with Calcium Phosphate Nanoparticles on the Integrity of the Bonded Resin Dentin Interface ADJ-for girls. 2017; 4:289-96

18. Shinohara MS, De Goes MF, Schneider LF, Ferracane JL, Pereira PN, Di Hipólito V, et al. Fluoride-containing adhesive: Durability on dentin bonding. Dent Mater. 2009;25:1383-91

19. Imazato S, Kinomoto Y, Tarumi H, Ebisu S, Tay FR. Antibacterial activity and bonding characteristics of an adhesive resin containing antibacterial monomer MDPB. Dent Mater. 2003; 19:313-9.

20. Lührs A-K, Guhr S, Schilke R, Borchers L, Geurtsen W,Günay H. Shear bond strength of self-etch adhesives to enamel with additional phosphoric acid etching. Oper. Dent., 2008; 33:155-62

21. Sai K, Takamizawa T, Imai A, Tsujimoto A, Ishii R, Barkmeier WW, Latta MA, Miyazaki M Influence of Application Time and Etching Mode of Universal Adhesives on Enamel Adhesion. J Adhes Dent. 2018; 20:65-77 
22. Ana Bedran-Russo, Ariene A. Leme-Kraus, Cristina M.P. Vidal, Erica C. Teixeira. An Overview of Dental Adhesive Systems and the Dynamic Tooth-Adhesive Interface. Dent. Clin. of North America, 2017; 61: 713-731

23. Raquel Osorio, Manuel Toledano, and Franklin GarciaGodoy. Bracket bonding with 15- or 60-second etching and adhesive remaining on enamel after debonding. The Angle Orthodontist. 1999;. 69: 45-48.
24. Hashimoto M,Ohno H, Kaga M,Sano,H, Tay,FR, Oguchi H, Araki Y, Kubota M. Over-etching effects on microtensile bond strength and failure patterns for two dentin bonding systems. J Dent. 2002; 30, 99-105,

25. Nguyen TT, Miller A, Orellana MF. Characterization of the porosity of human dental enamel and shear bond strength in vitro after variable etch times: initial findings using the BET method. Angle Orthod. 2011; 81:707-15 